\title{
The Immune-Related Gene ELF3 is a Novel Biomarker for the Prognosis of Ovarian Cancer
}

\author{
Hao Xu iD ${ }^{1, *}$ \\ Haihong Wang ${ }^{2, *}$ \\ Guilin $\mathrm{Li}^{3}$ \\ Xin Jin ${ }^{3}{ }^{3}$ \\ Buze Chen (iD) 2,4 \\ 'Department of Gynecology, Huangshi \\ Love \& Health Hospital Affiliated to \\ Hubei Polytechnic University, Huangshi, \\ 435000, Hubei, People's Republic of \\ China; ${ }^{2}$ Department of Gynecology, The \\ Affiliated Hospital of Xuzhou Medical \\ University, Xuzhou, 221000, Jiangsu, \\ People's Republic of China; ${ }^{3}$ Department \\ of Gynecology, Maternal and Child Health \\ Care Hospital Affiliated to Xuzhou \\ Medical University, Xuzhou, 221000, \\ Jiangsu, People's Republic of China; \\ ${ }^{4}$ Xuzhou Medical University, Xuzhou, \\ 221000, Jiangsu, People's Republic of \\ China \\ *These authors contributed equally to \\ this work
}

\begin{abstract}
Background: Ovarian cancer (OC) is a fatal gynaecological malignancy. The study aimed to conduct a comprehensive study to determine the role of ELF3 in OC through bioinformatic analysis.

Methods: Kruskal-Wallis test, Wilcoxon sign-rank test, and logistic regression were used to evaluate the relationship between clinical characteristics and ELF3 expression. KaplanMeier method and Cox regression analysis were used to evaluate the prognostic factors. Gene set enrichment analysis (GSEA) and immuno-infiltration analysis were used to evaluate the significant involvement of ELF3 in function.

Results: High ELF3 expression in OC was associated with age $(\mathrm{P}<0.001)$. High ELF3 expression predicted a poorer overall survival (OS) (HR: 1.37; 95\% CI: 1.05-1.78; P=0.019) and disease specific survival (DSS) (HR: 1.43; 95\% CI: 1.08-1.89; $\mathrm{P}=0.013$ ). And ELF3 expression (HR: 1.779; 95\% CI: 1.281-2.472; P<0.001) was independently correlated with OS in OC patients. GSEA demonstrated that pathways including GPCR-ligand binding, neuronal system, signaling by WNT, translation, neuroactive ligand-receptor interaction, and TCF dependent signaling in response to WNT were differentially enriched in ELF3 low expression phenotype. Immune infiltration analysis showed that ELF3 expression was correlated with immune infiltrates.
\end{abstract}

Conclusion: ELF3 expression in OC patients was significantly associated with poor survival and immune infiltration and a promising prognostic biomarker in OC.

Keywords: ovarian cancer, ELF3, prognosis, immune infiltrates, biomarkers

\section{Introduction}

Ovarian cancer (OC) is the most common gynaecological tumor, ranking fourth in incidence and third in mortality worldwide. ${ }^{1}$ In China, OC has the second highest mortality rate among gynaecological tumors and is on the rise, while the incidence is declining. ${ }^{2}$ High grade serous ovarian cancer (HGSOC) is the most common and fatal type of epithelial ovarian cancer, accounting for $75 \%$ of OC cases. $^{3}$ Non-epithelial ovarian cancer (NEOC) accounts for approximately $10 \%$ of all OC cases and includes malignancies of germ cell origin, malignancies of gonadal-stromal cell origin, small cell carcinomas and sarcomas. ${ }^{4}$ OC has no specific symptoms in its early stages, and over $70 \%$ of OC cases are diagnosed when the tumor has progressed to an advanced stage (stage III-IV; International Federation of Gynecology and Obstetrics, FIGO). ${ }^{5}$ Despite aggressive first-line surgery and adjuvant chemotherapy, the 5-year overall survival (OS) rate is still about $30 \%{ }^{6}$ The identification of key prognostic factors and predictive biomarkers is important to provide evidence for individualized treatment of OC.
Correspondence: Buze Chen Department of Gynecology, The Affiliated Hospital of Xuzhou Medical University, No. 99 West Huaihai Road, Quanshan District, Xuzhou, 221000, Jiangsu,

People's Republic of China

Tel +86-516 62020735

Email zku4ba@I63.com 
Transcription factor E74-like factor 3 (ELF3) is an epithelial-restricted member of the Ets transcription factor family. ${ }^{7}$ ELF-1 binds an essential repetitive GGAA cisacting element at the OAS1 promoter and cooperates with RB1 and SP1 recruitment to contribute to regulation in response to IFN stimulation. ${ }^{8}$ However, the relevance of ELF3 to immunity is also unclear. ELF3 is a well-documented tumor suppressor in some tumors, but shows oncogenic properties in others. ${ }^{9}$ ELF3 is an oncogene and putative therapeutic target in Lung adenocarcinoma (LUAD). ${ }^{9}$ ELF3 is a potential prognostic marker for patients with thyroid cancer (THCA) ${ }^{10}$ ELF3 is an independent prognostic factor for survival in HR+HER2+ breast cancer (BRCA) patients. ${ }^{11}$ ELF3 is a key driver of $\beta$-catenin signaling in colorectal cancer (CRC) and highlights the potential prognostic and therapeutic significance of ELF3 in CRC. ${ }^{12}$ ELF3 overexpression is a prognostic biomarker for recurrence of stage II in CRC. ${ }^{13}$ Although ELF3 has been shown to be a negative regulator of epithelial-mesenchymal transition (EMT) in OC cells, the detailed correlation between ELF3 and OC has not been studied. This study aims to explore the expression of ELF3 in OC, which may provide new directions for the development of diagnostic and therapeutic strategies for OC.

Based on the Cancer Genome Atlas (TCGA) database and OC RNA-seq data in GTEx, this study compared the differences in ELF3 expression between tumor tissues and normal samples, investigated the correlation between ELF3 expression and clinical features of OC, and assessed the prognostic value of ELF3 in OC patients. Genomic enrichment analysis (GSEA) was performed on ELF3 high and low ELF3 expression groups to reveal the possible functions of ELF3. The correlation between ELF3 expression and immune infiltration was analyzed to explore the potential mechanisms by which ELF3 regulates the onset and progression of OC.

\section{Materials and Methods}

\section{Differential Expression of ELF3}

Baseline information sheet. The analysis was carried out according to the literature. ${ }^{14}$ Target molecule: ELF3 [ENSG00000163435]. Subgroup: Median.

Unpaired samples. The analysis was carried out according to the literature. ${ }^{14,15}$ Target molecule: ELF3.

ROC Analysis. The analysis was carried out according to the literature. ${ }^{15,16}$ Target molecule: ELF3.
Table I Clinical Characteristics of OC Patients in TCGA

\begin{tabular}{|c|c|c|}
\hline Characteristic & Levels & Overall \\
\hline $\mathrm{n}$ & & 379 \\
\hline FIGO stage, n (\%) & $\begin{array}{l}\text { Stage I } \\
\text { Stage II } \\
\text { Stage III } \\
\text { Stage IV }\end{array}$ & $\begin{array}{l}\text { I }(0.3 \%) \\
23(6.1 \%) \\
295(78.5 \%) \\
57(15.2 \%)\end{array}$ \\
\hline $\begin{array}{l}\text { Primary therapy outcome, } \\
\text { n (\%) }\end{array}$ & $\begin{array}{l}\mathrm{PD} \\
\mathrm{SD} \\
\mathrm{PR} \\
\mathrm{CR}\end{array}$ & $\begin{array}{l}27(8.8 \%) \\
22(7.1 \%) \\
43(14 \%) \\
216(70.1 \%)\end{array}$ \\
\hline Race, n (\%) & $\begin{array}{l}\text { Asian } \\
\text { Black or African } \\
\text { American } \\
\text { White }\end{array}$ & $\begin{array}{l}12(3.3 \%) \\
25(6.8 \%) \\
328(89.9 \%)\end{array}$ \\
\hline Age, n (\%) & $\begin{array}{l}\leq 60 \\
>60\end{array}$ & $\begin{array}{l}208(54.9 \%) \\
|7|(45.1 \%)\end{array}$ \\
\hline Histologic grade, n (\%) & $\begin{array}{l}\text { GI } \\
\text { G2 } \\
\text { G3 } \\
\text { G4 }\end{array}$ & $\begin{array}{l}\text { I }(0.3 \%) \\
45(12.2 \%) \\
322(87.3 \%) \\
\text { I (0.3\%) }\end{array}$ \\
\hline $\begin{array}{l}\text { Anatomic neoplasm } \\
\text { subdivision, } \mathrm{n}(\%)\end{array}$ & $\begin{array}{l}\text { Unilateral } \\
\text { Bilateral }\end{array}$ & $\begin{array}{l}102(28.6 \%) \\
255(71.4 \%)\end{array}$ \\
\hline Venous invasion, $\mathrm{n}(\%)$ & $\begin{array}{l}\text { No } \\
\text { Yes }\end{array}$ & $\begin{array}{l}41(39 \%) \\
64(61 \%)\end{array}$ \\
\hline Lymphatic invasion, n (\%) & $\begin{array}{l}\text { No } \\
\text { Yes }\end{array}$ & $\begin{array}{l}48(32.2 \%) \\
101(67.8 \%)\end{array}$ \\
\hline Tumor residual, n (\%) & $\begin{array}{l}\text { NRD } \\
\text { RD }\end{array}$ & $\begin{array}{l}67(20 \%) \\
268(80 \%)\end{array}$ \\
\hline Age, median (IQR) & & $59(5 \mathrm{I}, 68)$ \\
\hline
\end{tabular}

\section{The Relationship Between ELF3 and Clinical Characteristics and Prognosis}

Correlation of gene expression with clinical characteristics. The analysis was carried out according to the literatures. ${ }^{17}$ Target molecule: ELF3. Clinical variables: Age.

Logistics analysis. The analysis was carried out according to the literatures. ${ }^{17}$ Dependent variable: ELF3.

\section{The Relationship Between ELF3 and Clinical Characteristics}

Kaplan-Meier method. The analysis was carried out according to the literatures. ${ }^{17,18}$ Target Molecule: ELF3. 

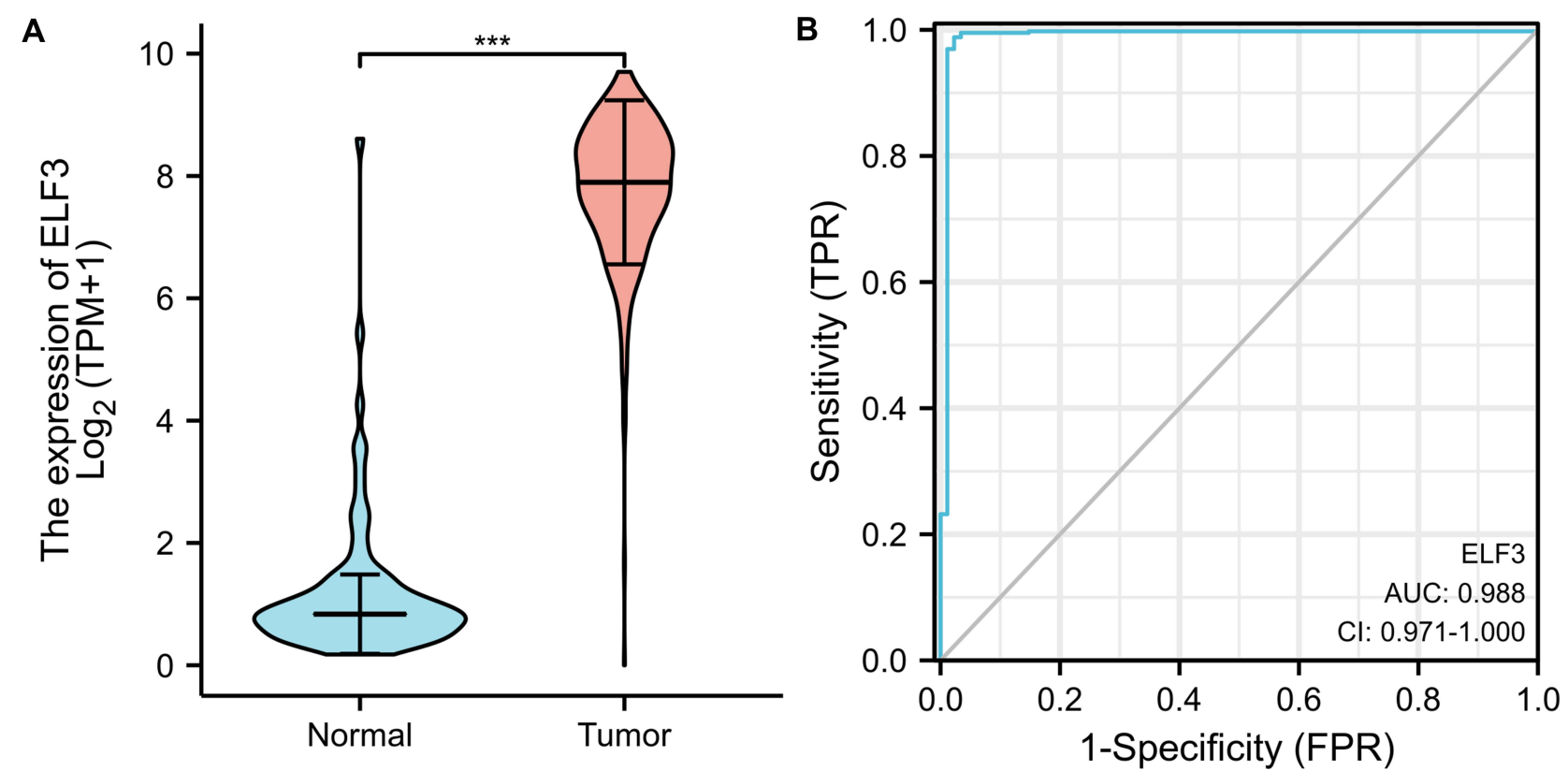

Figure I ELF3 is significantly upregulated in OC than normal tissues. (A) The difference expression of ELF3 in OC and normal ovarian tissues. (B) The efficiency of ELF3 expression levels in distinguishing OC from normal ovarian tissues. Significance markers: $*^{* * *} \mathrm{p}<0.00 \mathrm{I}$.

Prognosis type: OS and disease-specific survival (DSS). Subgroups: 0-50 vs 50-100.

COX regression. The analysis was carried out according to the literatures. ${ }^{17,18}$

Forest plot. Software: R (version 3.6.3). R package: ggplot2 package.

Nomogram plot. The analysis was carried out according to the literatures. ${ }^{17,18} \mathrm{R}$ package: rms package and survival package. Prognosis type: Overall Survival. Included variables: FIGO stage; Primary therapy outcome; Race; Age; Tumor residual; ELF3.

\section{Gene Set Enrichment Analysis (GSEA)}

Single gene differential analysis. The analysis was carried out according to the literatures. ${ }^{17,19}$ Target molecule: ELF3. Low expression group: 0-50\%. High expression group: $50-100 \%$.

GSEA analysis. The analysis was carried out according to the literatures. ${ }^{17,20,21}$

\section{Immune Infiltration Analysis by ssGSEA}

The analysis was carried out according to the literatures. $^{14,22,23}$ Target molecule: ELF3.

\section{Results}

\section{The Clinical Characteristics of OC Patients}

As shown in Table 1, the age range was 51 to 68 years, with a median of 59 years. There were 1 stage I (0.3\%), 23 stage II (6.1\%), 295 stage III (78.5\%), and 57 stage IV (15.2\%) in the FIGO stage. There were 27 PD (8.8\%), 22 SD (7.1\%), 43 PR (14\%), and $216 \mathrm{CR}(70.1 \%)$ in the primary therapy outcome. There were 328 white patients, 12 Asian patients, and 25 Black or African American patients in race. There were 208 patients $(\leq 60,54.9 \%)$ and 171 patients $(>60$, $45.1 \%)$ in the age. There were 1 G1 (1\%), 45 G2 (12.2\%), $322 \mathrm{G} 3(87.3 \%)$, and $1 \mathrm{G} 4(0.3 \%)$ in the histological grade. There were 102 unilateral $(28.6 \%)$ and 255 bilateral $(71.4 \%)$ in the anatomic neoplasm subdivision. There were 64 yes $(61 \%)$ and 41 no $(39 \%)$ in the venous invasion. There were 48 No $(32.2 \%)$ and 101 Yes $(67.8 \%)$ in the lymphatic invasion. There were $67 \mathrm{NRD}(20 \%)$ and $268 \mathrm{RD}(80 \%)$ in the tumor residual.

\section{ELF3 Expression is Correlated with Poor Clinicopathological Characteristics of $O C$} As shown in Figure 1A, ELF3 was highly expressed in OC tissues $(1.188 \pm 0.129$ vs $7.792 \pm 0.055, \mathrm{P}<0.001)$. As 
Table 2 Correlation of ELF3 Expression with Clinical Characteristics of OC Patients

\begin{tabular}{|c|c|c|c|}
\hline Characteristic & Low Expression of ELF3 & High Expression of ELF3 & $\mathbf{p}$ \\
\hline $\mathrm{n}$ & 189 & 190 & \\
\hline FIGO stage, n (\%) & & & 1.000 \\
\hline Stage I & I (0.3\%) & $0(0 \%)$ & \\
\hline Stage II & II (2.9\%) & 12 (3.2\%) & \\
\hline Stage III & $147(39.1 \%)$ & 148 (39.4\%) & \\
\hline Stage IV & $28(7.4 \%)$ & $29(7.7 \%)$ & \\
\hline Primary therapy outcome, $\mathrm{n}(\%)$ & & & 0.274 \\
\hline PD & $15(4.9 \%)$ & $12(3.9 \%)$ & \\
\hline SD & $15(4.9 \%)$ & 7 (2.3\%) & \\
\hline PR & $19(6.2 \%)$ & $24(7.8 \%)$ & \\
\hline CR & $106(34.4 \%)$ & $110(35.7 \%)$ & \\
\hline Race, n (\%) & & & 0.835 \\
\hline Asian & $5(1.4 \%)$ & 7 (I.9\%) & \\
\hline Black or African American & $13(3.6 \%)$ & $12(3.3 \%)$ & \\
\hline White & $163(44.7 \%)$ & $165(45.2 \%)$ & \\
\hline Age, n (\%) & & & $<0.001$ \\
\hline$\leq 60$ & $86(22.7 \%)$ & $122(32.2 \%)$ & \\
\hline$>60$ & $103(27.2 \%)$ & $68(17.9 \%)$ & \\
\hline Histologic grade, n (\%) & & & 0.722 \\
\hline GI & I (0.3\%) & $0(0 \%)$ & \\
\hline G2 & $24(6.5 \%)$ & $21(5.7 \%)$ & \\
\hline G3 & $160(43.4 \%)$ & $162(43.9 \%)$ & \\
\hline G4 & $0(0 \%)$ & I (0.3\%) & \\
\hline Anatomic neoplasm subdivision, $\mathrm{n}(\%)$ & & & 0.073 \\
\hline Unilateral & $57(16 \%)$ & $45(12.6 \%)$ & \\
\hline Bilateral & $114(31.9 \%)$ & $|4|(39.5 \%)$ & \\
\hline Venous invasion, $\mathrm{n}(\%)$ & & & 0.938 \\
\hline No & $21(20 \%)$ & $20(19 \%)$ & \\
\hline Yes & 31 (29.5\%) & $33(31.4 \%)$ & \\
\hline Lymphatic invasion, n (\%) & & & 0.250 \\
\hline No & $26(17.4 \%)$ & $22(14.8 \%)$ & \\
\hline Yes & $43(28.9 \%)$ & $58(38.9 \%)$ & \\
\hline Tumor residual, $\mathrm{n}(\%)$ & & & 0.848 \\
\hline NRD & $34(10.1 \%)$ & $33(9.9 \%)$ & \\
\hline RD & $130(38.8 \%)$ & $138(41.2 \%)$ & \\
\hline Age, median (IQR) & $62(52,71)$ & $57(49.25,65)$ & $<0.001$ \\
\hline
\end{tabular}

shown in Figure 1B, the area under curve (AUC) of ELF3 was 0.988 , suggesting that ELF3 could be served as an ideal biomarker to distinguish $\mathrm{OC}$ from nontumor tissue. As shown in Table 2, ELF3 expression was associated with age $(\mathrm{P}<0.001)$. The Logistic regression results in Figure 2 and Table 3 suggested that ELF3 was significantly related to age (HR: 0.465 ; $95 \%$ CI: $0.307-0.701$; $\mathrm{P}<0.001)$. 


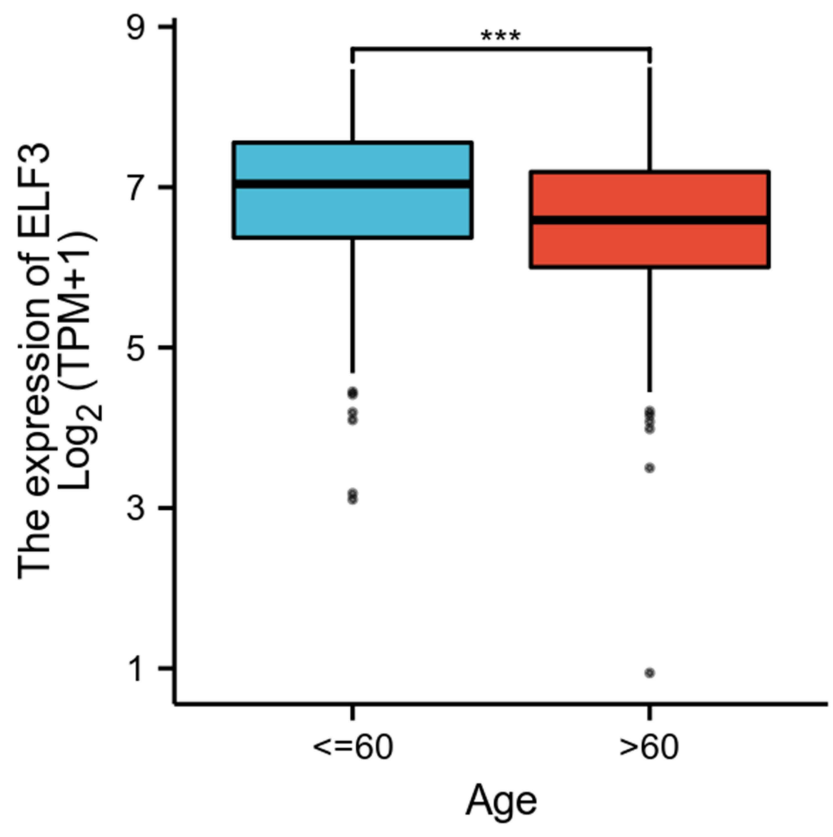

Figure 2 The relationship between ELF3 expression and age of OC patients. Significance markers: $* * * p<0.001$.

\section{Role of ELF3 in OC Patient Survival}

The expression of ELF3 was positively correlated with poor OS (HR: 1.37; 95\% CI: 1.05-1.78; $\mathrm{P}=0.019$ ) and DSS (HR: $1.43 ; 95 \% \mathrm{CI}: 1.08-1.89 ; \mathrm{P}=0.013$ ) of $\mathrm{OC}$ patients (Figure 3). As shown in Table 4, high ELF3 expression levels were associated with worse OS (HR: $1.368,1.054-1.775, \mathrm{P}=0.019)$, primary therapy outcome (HR: 0.229, 95\% CI: 0.166-0.318, $\mathrm{P}<0.001$ ), age (HR:
1.355, 95\% CI: 1.046-1.754, $\mathrm{P}=0.021)$, and tumor residual (HR: 2.313, 95\% CI: 1.486-3.599, $\mathrm{P}<0.001$ ). As in Table 4 and Figure 4, ELF3 (HR: 1.779; 95\% CI: 1.281-2.472; $\mathrm{P}<0.001$ ), primary therapy outcome (HR: 0.245 ; 95\% CI: $0.170-0.354 ; \mathrm{P}<0.001$ ), and age (HR: 1.498; 95\% CI: 1.082-2.073; $\mathrm{P}=0.015)$ were independently correlated with OS in multivariate analysis. The above data indicated ELF3 is a prognostic factor and increased ELF3 level is associated with poor OS. A nomogram was constructed to predict the 1-, 3-, and 5-year survival probability of OC patients by combining the expression level of ELF3 with clinical variables, as shown in Figure 5.

\section{ELF3-Related Pathways Based on GSEA}

There were 111 data sets which showed significantly differential enrichment in ELF3 low expression phenotype, and we selected the top 9 data sets with high value of normalized enrichment score (NES), in Table 5 and Figure 6, including GPCR-ligand binding, neuronal system, signaling by WNT, translation, neuroactive ligandreceptor interaction, TCF dependent signaling in response to WNT, core matrisome, signaling by ROBO receptors, and anti-inflammatory response favouring Leishmania parasite infection.

\section{The Correlation Between ELF3 Expression and Immune Infiltration}

As shown in Figure 7 and Table 6, analysis of the relationship between ELF3 and immune infiltration based on ssGSEA

Table 3 Correlation Between ELF3 Expression and Clinical Characteristics (Logistic Analysis)

\begin{tabular}{|l|l|l|l|}
\hline Characteristics & Total (N) & Odds Ratio (OR) & P value \\
\hline FIGO stage (Stage III \& Stage IV vs Stage I \& Stage II) & 376 & I.0II (0.438-2.335) & 0.979 \\
\hline Primary therapy outcome (CR vs PD\&SD\&PR) & 308 & $1.183(0.726-1.932)$ & $0.50 I$ \\
\hline Race (White vs Asian \& Black or African American) & 365 & $0.959(0.483-1.899)$ & 0.904 \\
\hline Age (>60 vs $\leq 60)$ & 379 & $0.465(0.307-0.701)$ & $<0.001$ \\
\hline Histologic grade (G3\&G4 vs GI\&G2) & 369 & $1.213(0.653-2.272)$ & 0.542 \\
\hline Anatomic neoplasm subdivision (Bilateral vs Unilateral) & 357 & $1.567(0.988-2.496)$ & 0.057 \\
\hline Venous invasion (Yes vs No) & 105 & $1.118(0.509-2.460)$ & $0.78 I$ \\
\hline Lymphatic invasion (Yes vs No) & 149 & $1.594(0.800-3.204)$ & 0.186 \\
\hline Tumor residual (RD vs NRD) & 335 & $1.094(0.639-1.873)$ & 0.743 \\
\hline
\end{tabular}



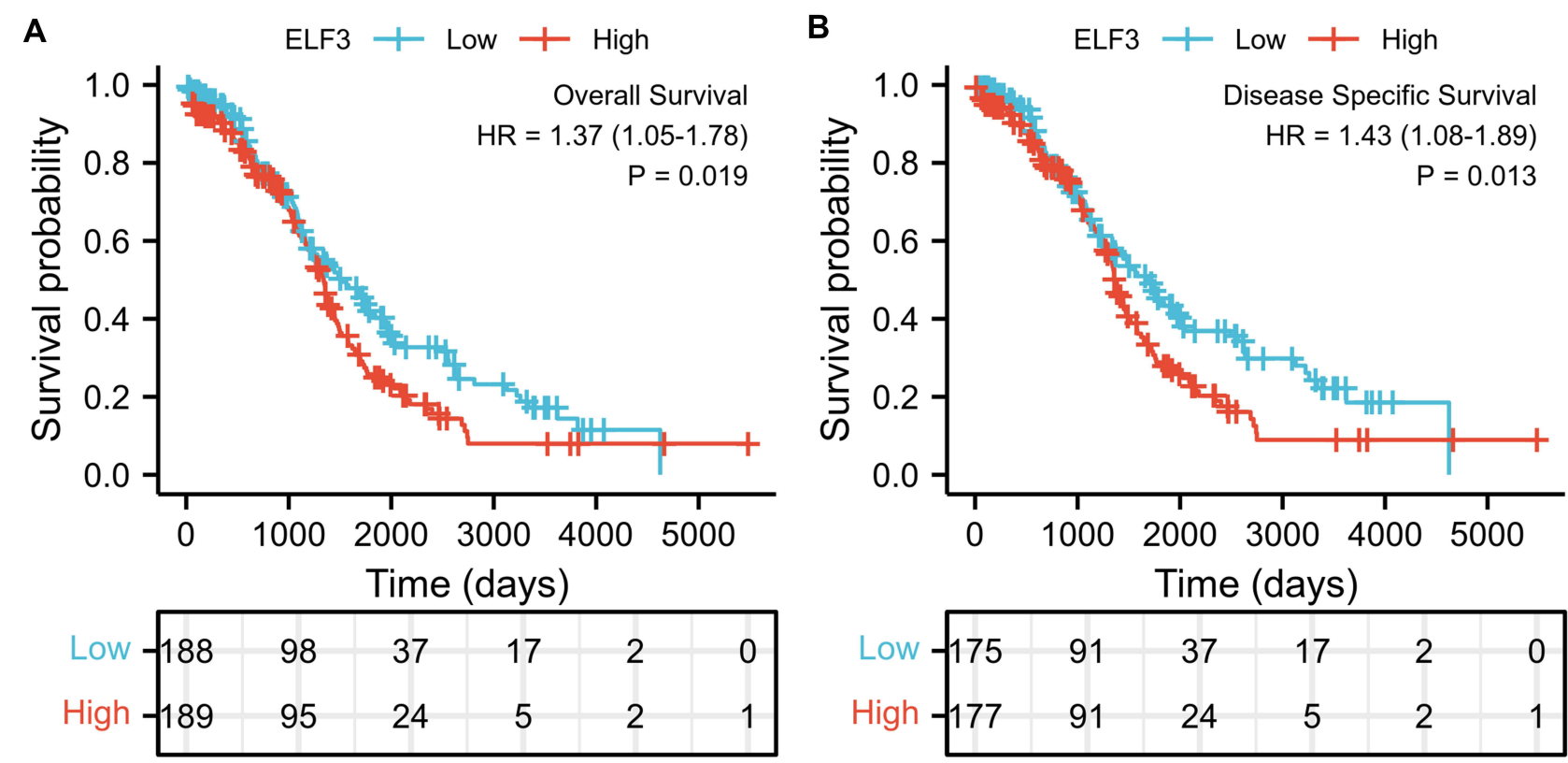

Figure 3 High expression of ELF3 in OC patients is associated with poor OS and DSS. (A) OS, over survival; (B) DSS, disease-specific survival.

with Spearman $r$ showed that showed that ELF3 expression was positively correlated with that of $\mathrm{aDC}(\mathrm{P}<0.001), \mathrm{CD} 8 \mathrm{~T}$ cells $(\mathrm{P}=0.003)$, cytotoxic cells $(\mathrm{P}<0.001), \mathrm{DC}(\mathrm{P}=0.016)$, Eosinophils $\quad(\mathrm{P}=0.018), \quad$ iDC $\quad(\mathrm{P}=0.029)$, Macrophages
( $\mathrm{P}=0.016)$, Mast cells $(\mathrm{P}=0.049)$, Neutrophils $(\mathrm{P}<0.001)$, NK CD56bright cells $(\mathrm{P}=0.001)$, NK CD56dim cells $(\mathrm{P}=0.01), \quad$ Tcm $\quad(\mathrm{P}<0.001)$, Tem $\quad(\mathrm{P}=0.002), \quad$ Th1 cells $(\mathrm{P}=0.001)$, Th17 cells $(\mathrm{P}<0.001)$, and TReg $(\mathrm{P}=0.008)$.

Table 4 Univariate and Multivariate Analysis (Cox Regression) Between OS and Clinical Characteristics in OC Patients

\begin{tabular}{|c|c|c|c|c|c|}
\hline \multirow[t]{2}{*}{ Characteristics } & \multirow[t]{2}{*}{ Total (N) } & \multicolumn{2}{|l|}{ Univariate Analysis } & \multicolumn{2}{|l|}{ Multivariate Analysis } \\
\hline & & Hazard Ratio ( $95 \% \mathrm{Cl})$ & $P$ value & Hazard Ratio (95\% Cl) & $P$ value \\
\hline FIGO stage (Stage III \& Stage IV vs Stage I \& Stage II) & 374 & $2.115(0.938-4.766)$ & 0.071 & $2.868(0.694-11.842)$ & 0.145 \\
\hline Primary therapy outcome (CR vs PD\&SD\&PR) & 307 & $0.229(0.166-0.318)$ & $<0.001$ & $0.245(0.170-0.354)$ & $<0.001$ \\
\hline Race (White vs Asian \& Black or African American) & 364 & $0.637(0.405-1.004)$ & 0.052 & $1.107(0.614-1.993)$ & 0.736 \\
\hline Age $(>60$ vs $\leq 60)$ & 377 & $1.355(1.046-1.754)$ & 0.021 & $1.498(1.082-2.073)$ & 0.015 \\
\hline Histologic grade (G3\&G4 vs GI\&G2) & 367 & $1.229(0.830-1.818)$ & 0.303 & & \\
\hline Anatomic neoplasm subdivision (Bilateral vs Unilateral) & 356 & $1.049(0.776-1.418)$ & 0.757 & & \\
\hline Venous invasion (Yes vs No) & 105 & $0.896(0.487-1.649)$ & 0.723 & & \\
\hline Lymphatic invasion (Yes vs No) & 148 & $1.413(0.833-2.396)$ & 0.200 & & \\
\hline Tumor residual (RD vs NRD) & 334 & $2.313(1.486-3.599)$ & $<0.001$ & $1.685(0.990-2.869)$ & 0.054 \\
\hline ELF3 (High vs Low) & 377 & $1.368(1.054-1.775)$ & 0.019 & $1.779(1.28 \mid-2.472)$ & $<0.001$ \\
\hline
\end{tabular}




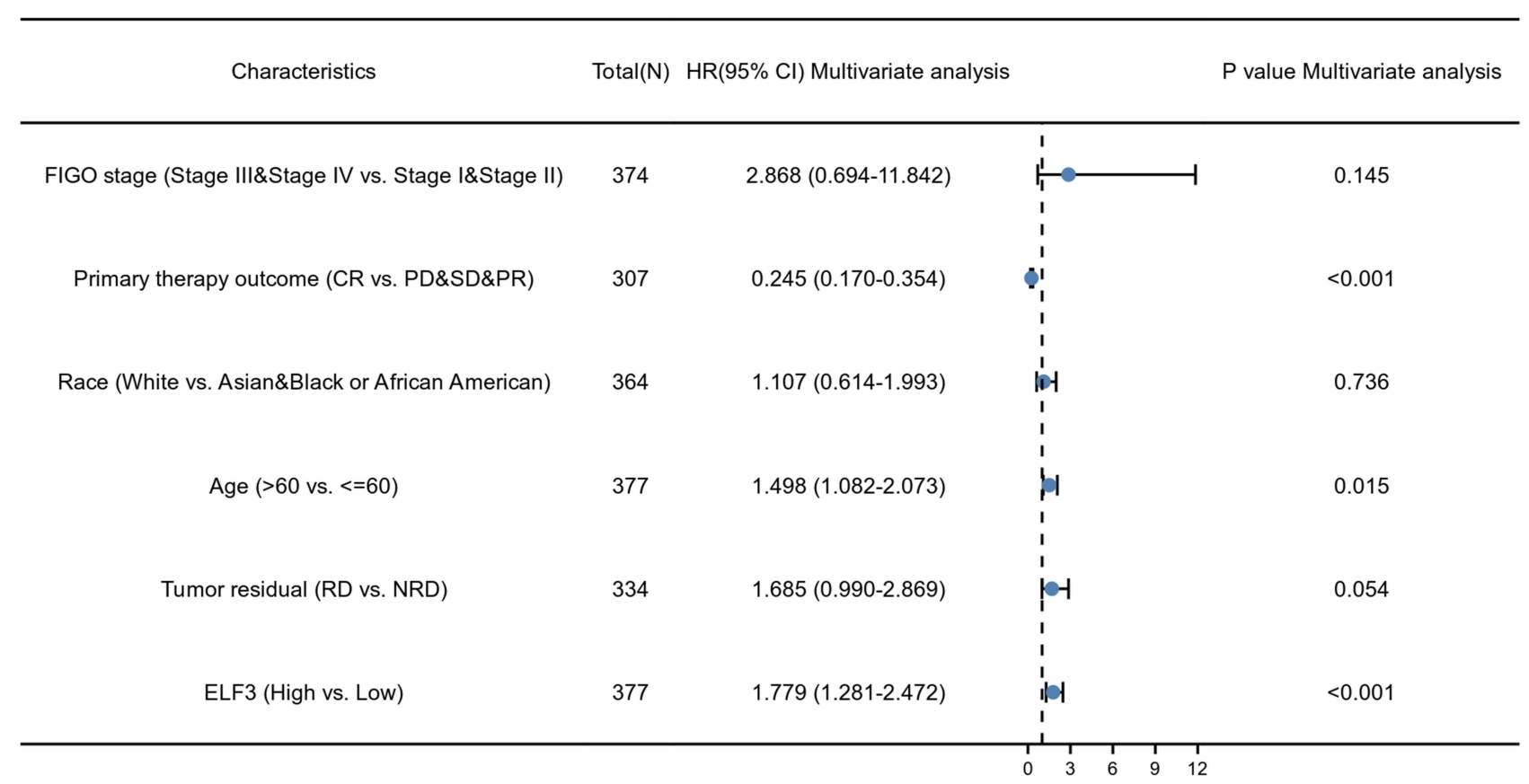

Figure 4 Forest plot of the multivariate Cox regression analysis in OC.

Points

FIGO stage

Primary therapy outcome

Race

Age

Tumor residual

ELF3

Total Points

Linear Predictor

1-year Survival Probability

3-year Survival Probability

5-year Survival Probability

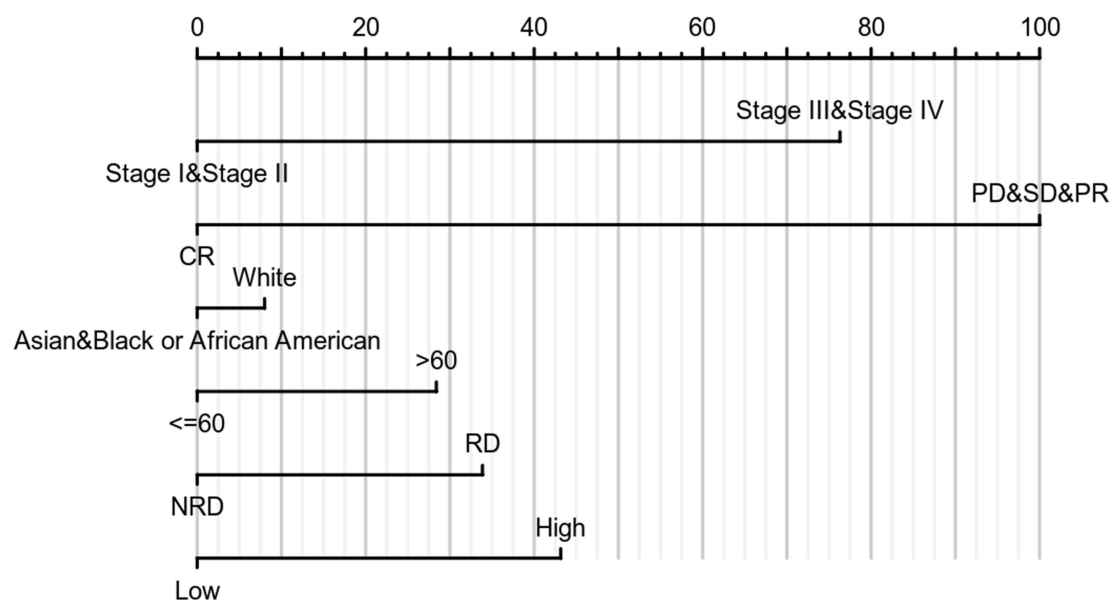

Figure 5 Nomogram for predicting the probability of patients with I-, 3- and 5-year overall survival. 
Table 5 Gene Sets Enriched in the ELF3 Low Expression Group

\begin{tabular}{|c|c|c|c|}
\hline Description & NES & P Adjust & q values \\
\hline REACTOME_GPCR_LIGAND_BINDING & -1.420 & 0.033 & 0.023 \\
\hline REACTOME_NEURONAL_SYSTEM & -1.463 & 0.033 & 0.023 \\
\hline REACTOME_SIGNALING_BY_WNT & -1.530 & 0.033 & 0.023 \\
\hline REACTOME_TRANSLATION & -1.577 & 0.033 & 0.023 \\
\hline KEGG_NEUROACTIVE_LIGAND_RECEPTOR_INTERACTION & -1.601 & 0.033 & 0.023 \\
\hline NABA_CORE_MATRISOME & -1.593 & 0.033 & 0.023 \\
\hline REACTOME_TCF_DEPENDENT_SIGNALING_IN_RESPONSE_TO_WNT & -1.663 & 0.033 & 0.023 \\
\hline REACTOME_ANTI_INFLAMMATORY_RESPONSE_FAVOURING_LEISHMANIA_PARASITE_INFECTION & -1.661 & 0.033 & 0.023 \\
\hline REACTOME_SIGNALING_BY_ROBO_RECEPTORS & -1.898 & 0.033 & 0.023 \\
\hline
\end{tabular}

\section{Discussion}

Despite the many advances that have been made in treatment strategies for OC, OS has not improved in these patients and the search for novel biomarkers that can be used to predict the prognosis of these patients is warranted. SLC7A2 is a novel biomarker for the diagnosis and treatment of OC. ${ }^{24}$ PRDX-1 expression in tumor tissue can be a biomarker for the prognosis of patients with OC. ${ }^{25}$ Increased expression of TET3 predicts an unfavorable prognosis for OC patients. ${ }^{26}$ Low expression of BCL7A is an independent risk factor for poor prognosis in patients with OC. ${ }^{27}$ Overexpression of PRC1 indicates poor prognosis of OC. ${ }^{28}$ Therefore, it is important to study mRNAs as new OC biomarkers and therapeutic targets in the future.

The high expression of ELF3 in OC patients in this study was significantly associated with age $(\mathrm{P}<0.001)$. The expression of ELF3 is high in subjects with age $(\leq 60)$ and low in subjects with age $(>60)$. The reasons for this are subject to further research. High ELF3 expression predicted a poorer OS (HR: 1.37 ; 95\% CI: 1.05-1.78; $\mathrm{P}=0.019$ ) and DSS (HR: 1.43 ; 95\% CI: $1.08-1.89$; $\mathrm{P}=0.013$ ). And ELF3 expression (HR: 1.779; 95\% CI: $1.281-2.472 ; \mathrm{P}<0.001)$ was independently correlated with OS in OC patients. Therefore, ELF3 can be used as a promising prognostic marker for patients with OC.
ELF3 forms a positive feedback loop with the MAPK pathway, leading to the progression of BRAFmutant THCA. $^{10}$ The miR-1224-5p/ELF3 axis may serve as a novel diagnostic, therapeutic, and prognostic biomarker for pancreatic cancer (PAAD) and the associated PI3K/AKT/Notch/EMT signaling pathway greatly contributes to the progression of PAAD. ${ }^{29}$ The MiR320a-3p/ELF3 axis regulates cell metastasis and invasion in non-small cell lung cancer (NSCLC) through the PI3K/Akt pathway. ${ }^{30}$ In this study, ELF3 was found to be associated with the pathways GPCR-ligand binding, neuronal system, signaling by WNT, translation, neuroactive ligand-receptor interaction, TCF dependent signaling in response to WNT, core matrisome, signaling by ROBO receptors, and anti-inflammatory response favoring Leishmania parasite infection based on GESA analysis.

Immune infiltration in $\mathrm{OC}$ is currently a hot topic and knowledge of immune infiltrating cells is beneficial to the development of immunotherapy for OC. Early efforts in this approach evaluated cytokine therapy for OC, but failed to present convincing Phase III data. ${ }^{31}$ On the other hand, immune checkpoint inhibitors (ICIs) have emerged as important immune stimulants and the immunological properties of OC provide a basis for their introduction into disease management. ${ }^{31}$ However, 

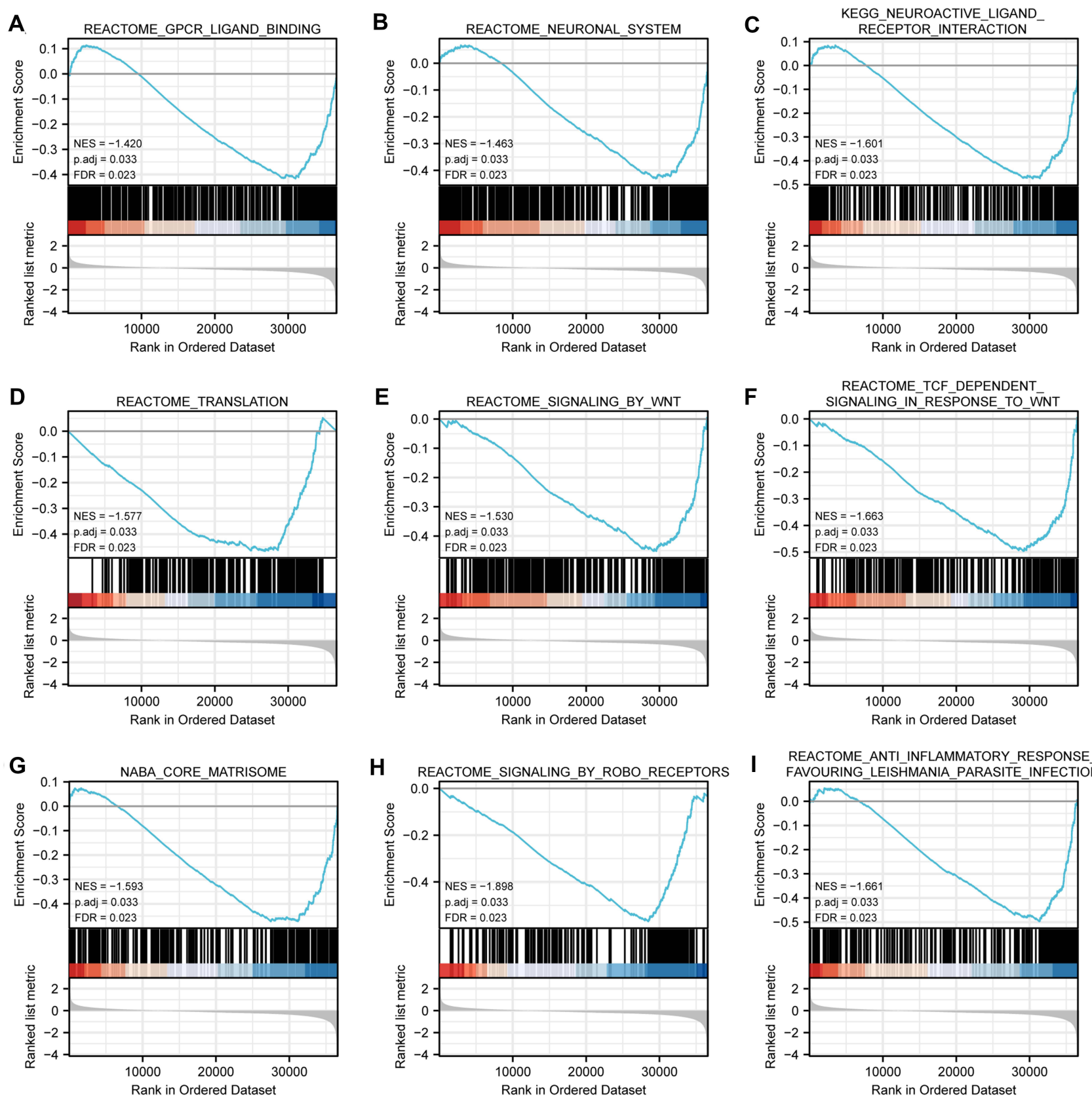

Figure 6 Enrichment plots from gene set enrichment analysis (GSEA). (A) GPCR-ligand binding, (B) neuronal system, (C) neuroactive ligand-receptor interaction, (D) translation, (E) signaling by WNT, (F) TCF dependent signaling in response to WNT, (G) core matrisome, (H) signaling by ROBO receptors and (I) anti-inflammatory response favoring Leishmania parasite infection.

Abbreviations: NES, normalized ES; FDR, false discovery rate.

when evaluated in pretreated patients with OC, ICIs have delivered only modest efficacy as monotherapy, necessitating additional approaches to realize the potential. ${ }^{31}$ Since then, several strategies have aimed to sensitive $\mathrm{OC}$ to immunotherapy by combining it with chemotherapy, anti-angiogenics, PARPi, radiotherapy, and dual immune checkpoint blockade. ${ }^{31}$ The present study showed that ELF3 expression was associated 


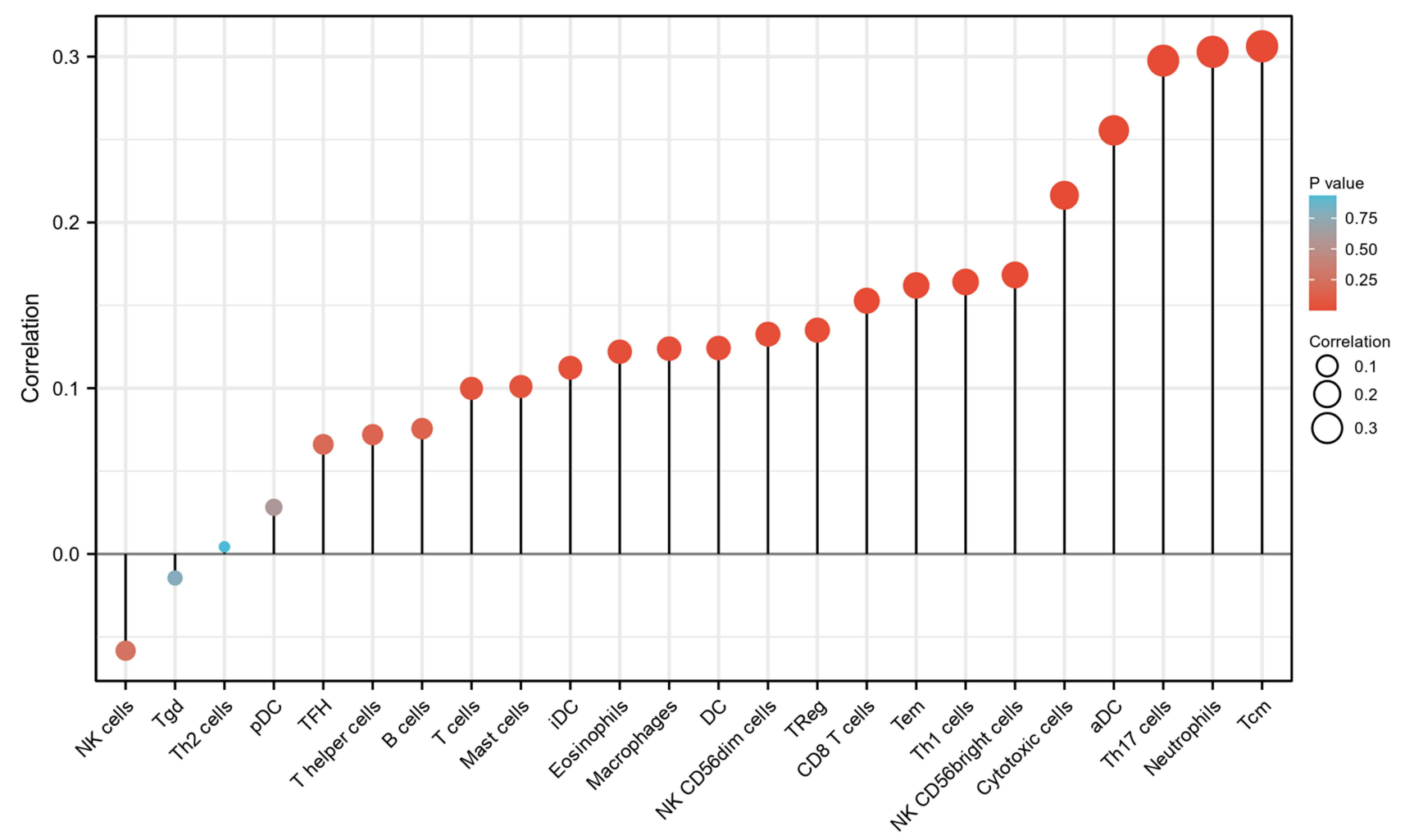

Figure 7 The expression level of ELF3 was related to the immune infiltration in the tumor microenvironment. The forest plot shows the correlation between ELF3 expression level and 24 immune cells. The size of dots indicates the absolute value of Spearman $r$.

with infiltration of aDC, CD8 T cells, Cytotoxic cells, DC, Eosinophils, iDC, Macrophages, Mast cells, Neutrophils, NK CD56bright cells, NK CD56dim cells, Tcm, Tem, Th1 cells, Th17 cells, and TReg in OC. This means that ELF3 promotes the function of aDC, CD8 T cells, Cytotoxic cells, DC, Eosinophils, iDC, Macrophages, Mast cells, Neutrophils, NK CD56bright cells, NK CD56dim cells, Tcm, Tem, Th1 cells, Th17 cells, and TReg.

This study explored the relationship between ELF3 and OC. However, there are some limitations to this study. This study was based on RNA sequencing from the TCGA database and we were unable to describe the specific molecular mechanisms of ELF3 in OC patients. The specific molecular mechanisms by which ELF3 mediates OC occurrence and development were further investigated.

\section{Conclusion}

ELF3 was highly expressed in OC tissues and significantly associated with poor OS and DSS in OC patients. ELF3 is involved in the development and progression of OC through pathways including GPCR-ligand binding, neuronal system, signaling by WNT, translation, neuroactive ligand-receptor interaction, TCF dependent signaling in response to WNT, core matrisome, signaling by ROBO receptors, anti-inflammatory response favoring Leishmania parasite infection. ELF3 was associated with immune infiltrating cells. This study suggested that ELF3 was a promising prognostic biomarker for ovarian cancer.

\section{Data Sharing Statement}

All data generated or analyzed during this study are included in this published article. 
Table 6 ELF3 Expression Associated with Immune Cells (Spearman Method)

\begin{tabular}{|l|l|l|l|}
\hline Gene Name & Cell Type & $\begin{array}{l}\text { Correlation } \\
\text { Coefficient }\end{array}$ & $\begin{array}{l}\text { P value } \\
\text { (Spearman) }\end{array}$ \\
& & (Spearman) & \\
\hline ELF3 & aDC & 0.256 & $<0.001$ \\
ELF3 & B cells & 0.076 & 0.142 \\
ELF3 & CD8 T cells & 0.153 & 0.003 \\
ELF3 & Cytotoxic cells & 0.216 & $<0.001$ \\
ELF3 & DC & 0.124 & 0.016 \\
ELF3 & Eosinophils & 0.122 & 0.018 \\
ELF3 & iDC & 0.112 & 0.029 \\
ELF3 & Macrophages & 0.124 & 0.016 \\
ELF3 & Mast cells & 0.101 & 0.049 \\
ELF3 & Neutrophils & 0.303 & $<0.001$ \\
ELF3 & NK CD56bright cells & 0.168 & 0.001 \\
ELF3 & NK CD56dim cells & 0.133 & 0.01 \\
ELF3 & NK cells & -0.058 & 0.257 \\
ELF3 & pDC & 0.028 & 0.585 \\
ELF3 & T cells & 0.1 & 0.052 \\
ELF3 & T helper cells & 0.072 & 0.162 \\
ELF3 & Tcm & 0.306 & $<0.001$ \\
ELF3 & Tem & 0.162 & 0.002 \\
ELF3 & TFH & 0.066 & 0.199 \\
ELF3 & Tgd & -0.014 & 0.779 \\
ELF3 & Th1 cells & 0.164 & $<0.001$ \\
ELF3 & Th17 cells & 0.934 \\
ELF3 & Th2 cells & 0.008 \\
ELF3 & TReg & \\
\hline
\end{tabular}

\section{Acknowledgments}

The datasets generated in this study are available from TCGA that provide free resources.

\section{Author Contributions}

All authors contributed to data analysis, drafting or revising the article, have agreed on the journal to which the article will be submitted, gave final approval of the version to be published, and agree to be accountable for all aspects of the work.

\section{Funding}

This work was supported by Natural Science Foundation of Hubei Province (WJ2019H205).

\section{Disclosure}

The authors declare that they have no competing interests.

\section{References}

1. Bray F, Ferlay J, Soerjomataram I, Siegel RL, Torre LA, Jemal A. Global cancer statistics 2018: GLOBOCAN estimates of incidence and mortality worldwide for 36 cancers in 185 countries. CA Cancer J Clin. 2018;68(6):394-424.

2. Chen W, Zheng R, Baade PD, et al. Cancer statistics in China, 2015. CA Cancer J Clin. 2016;66(2):115-132.

3. Chen B, Liu S, Wang H, Li G, Lu X, Xu H. Differential expression profiles and function prediction of transfer RNA-derived fragments in high-grade serous ovarian cancer. Biomed Res Int. 2021;2021:5594081.

4. Boussios S, Moschetta M, Zarkavelis G, Papadaki A, Kefas A, Tatsi K. Ovarian sex-cord stromal tumours and small cell tumours: pathological, genetic and management aspects. Crit Rev Oncol Hematol. 2017;120:43-51. doi:10.1016/j.critrevonc.2017.10.007

5. Zeppernick F, Meinhold-Heerlein I. The new FIGO staging system for ovarian, fallopian tube, and primary peritoneal cancer. Arch Gynecol Obstet. 2014;290(5):839-842. doi:10.1007/s00404-014-3364-8

6. Matulonis UA, Sood AK, Fallowfield L, Howitt BE, Sehouli J, Karlan BY. Ovarian cancer. Nat Rev Dis Prim. 2016;2:16061.

7. Wasylyk B, Hagman J, Gutierrez-Hartmann A. Ets transcription factors: nuclear effectors of the Ras-MAP-kinase signaling pathway. Trends Biochem Sci. 1998;23(6):213-216. doi:10.1016/S0968-0004 (98)01211-0

8. Larsen S, Kawamoto S, Tanuma S, Uchiumi F. The hematopoietic regulator, ELF-1, enhances the transcriptional response to Interferon$\beta$ of the OAS1 anti-viral gene. Sci Rep. 2015;5(1):17497. doi:10.1038/srep17497

9. Enfield KSS, Marshall EA, Anderson C, et al. Epithelial tumor suppressor ELF3 is a lineage-specific amplified oncogene in lung adenocarcinoma. Nat Commun. 2019;10(1):5438. doi:10.1038/ s41467-019-13295-y

10. Chen H, Chen W, Zhang X, et al. E26 transformation (ETS)-specific related transcription factor-3 (ELF3) orchestrates a positive feedback loop that constitutively activates the MAPK/Erk pathway to drive thyroid cancer. Oncol Rep. 2019;41(1):570-578.

11. Kar A, Koto K, Walker D, et al. ETS transcription factor ESE-1/Elf3 is an independent prognostic factor of survival in HR(+)HER2(+) breast cancer patients. Breast Cancer Res Treat. 2020;182(3):601612. doi:10.1007/s10549-020-05734-y

12. Wang JL, Chen ZF, Chen HM, et al. Elf3 drives $\beta$-catenin transactivation and associates with poor prognosis in colorectal cancer. Cell Death Dis. 2014;5(5):e1263. doi:10.1038/cddis.2014.206

13. Takaoka A, Ishikawa T, Okazaki S, et al. ELF3 overexpression as prognostic biomarker for recurrence of stage II colorectal cancer. In Vivo (Brooklyn). 2021;35(1):191-201. doi:10.21873/invivo.12248

14. Lu X, Li G, Liu S, Wang H, Zhang Z, Chen B. Bioinformatics analysis of KIF1A expression and gene regulation network in ovarian carcinoma. Int J Gen Med. 2021;14:3707-3717. doi:10.2147/IJGM. S323591

15. Vivian J, Rao AA, Nothaft FA, et al. Toil enables reproducible, open source, big biomedical data analyses. Nat Biotechnol. 2017;35 (4):314-316. doi:10.1038/nbt.3772

16. Chen J, Tang H, Li T, et al. Comprehensive analysis of the expression, prognosis, and biological significance of OVOLs in breast cancer. Int J Gen Med. 2021;14:3951-3960. doi:10.2147/IJGM. S326402

17. Chen T, Zhu C, Wang X, Pan Y. LncRNA ELF3-AS1 is a prognostic biomarker and correlated with immune infiltrates in hepatocellular carcinoma. Can J Gastroenterol Hepatol. 2021;2021:8323487. doi:10.1155/2021/8323487 
18. Liu J, Lichtenberg T, Hoadley KA, et al. An integrated TCGA pancancer clinical data resource to drive high-quality survival outcome analytics. Cell. 2018;173(2):400-416.e411.

19. Love MI, Huber W, Anders S. Moderated estimation of fold change and dispersion for RNA-seq data with DESeq2. Genome Biol. 2014;15(12):550. doi:10.1186/s13059-014-0550-8

20. Yu G, Wang LG, Han Y, He QY. clusterProfiler: an R package for comparing biological themes among gene clusters. OMICS. 2012;16 (5):284-287. doi:10.1089/omi.2011.0118

21. Subramanian A, Tamayo P, Mootha VK, et al. Gene set enrichment analysis: a knowledge-based approach for interpreting genome-wide expression profiles. Proc Natl Acad Sci USA. 2005;102(43):1554515550. doi:10.1073/pnas.0506580102

22. Hänzelmann S, Castelo R, Guinney J. GSVA: gene set variation analysis for microarray and RNA-seq data. BMC Bioinform. 2013;14(1):7. doi:10.1186/1471-2105-14-7

23. Bindea G, Mlecnik B, Tosolini M, et al. Spatiotemporal dynamics of intratumoral immune cells reveal the immune landscape in human cancer. Immunity. 2013;39(4):782-795. doi:10.1016/j.immu ni.2013.10.003

24. Sun T, Bi F, Liu Z, Yang Q. SLC7A2 serves as a potential biomarker and therapeutic target for ovarian cancer. Aging. 2020;12(13):1328113296. doi:10.18632/aging.103433
25. Sieńko J, Teliga-Czajkowska J, Przytula E, Czajkowski K, Smolarczyk R, Nowis D. Peroxiredoxin-1 as a prognostic factor in patients with ovarian cancer. Ann Agric Environ Med. 2019;26 (3):415-419. doi:10.26444/aaem/105899

26. Cao T, Pan W, Sun X, Shen H. Increased expression of TET3 predicts unfavorable prognosis in patients with ovarian cancer-A bioinformatics integrative analysis. J Ovarian Res. 2019;12(1):101.

27. Sun Z, Sun L, He M, Pang Y, Yang Z, Wang J. Low BCL7A expression predicts poor prognosis in ovarian cancer. $J$ Ovarian Res. 2019;12(1):41. doi:10.1186/s13048-019-0518-0

28. $\mathrm{Bu} \mathrm{H}$, Li Y, Jin C, et al. Overexpression of PRC1 indicates a poor prognosis in ovarian cancer. Int J Oncol. 2020;56(3):685-696.

29. Kong L, Liu P, Zheng M, et al. The miR-1224-5p/ELF3 axis regulates malignant behaviors of pancreatic cancer via PI3K/AKT/notch signaling pathways. Onco Targets Ther. 2020;13:3449-3466. doi:10.2147/OTT.S248507

30. Zhao W, Sun Q, Yu Z, et al. MiR-320a-3p/ELF3 axis regulates cell metastasis and invasion in non-small cell lung cancer via PI3K/Akt pathway. Gene. 2018;670:31-37. doi:10.1016/j.gene.2018.05.100

31. Demircan NC, Boussios S, Tasci T, Öztürk MA. Current and future immunotherapy approaches in ovarian cancer. Ann Transl Med. 2020;8(24):1714. doi:10.21037/atm-20-4499
International Journal of General Medicine

\section{Publish your work in this journal}

The International Journal of General Medicine is an international, peer-reviewed open-access journal that focuses on general and internal medicine, pathogenesis, epidemiology, diagnosis, monitoring and treatment protocols. The journal is characterized by the rapid reporting of reviews, original research and clinical studies

\section{Dovepress}

across all disease areas. The manuscript management system is completely online and includes a very quick and fair peer-review system, which is all easy to use. Visit http://www.dovepress.com/ testimonials.php to read real quotes from published authors. 